\title{
SuRVEYING VARIOUS EFFECTIVE PARAMETERS ON A Y-SHAPE PARTHYDROFORMING USING FEM AND Process OPTIMIZATION BY NuMERICAL METHODS
}

\author{
Amir Rahimi ${ }^{1 *}$ \\ ${ }^{1}$ Imam Khomeini Oil Refining Company, Arak, Iran \\ *Department of Mechanical Engineering, Isfahan University of Technology, Isfahan, Iran \\ amir.2482@gmail.com
}

\begin{abstract}
Tube hydroforming process in order to manufacture complex partsperfectly, for example y-shapes; demands precise loading paths, Otherwise because of complexity of these parts, some deficiencies like wrinkling, bursting or imperfect forming may occur. Finding an effective combination of applied forces depends on repeating experimental experience numerously which in turn needs a lot of time and cost.So using numerical simulations, which are remarkably faster and cheaper than practical experiments, can resolve this problem influentially. In this study firstly a y-shape was modelled using FEA software and then obtained results were compared with experimental ones to verify and confirm the simulation precision. In the next step objective and constraints functions were defined using Neural Network. To do this, simulation was repeated in certain numbers and needed Neural Networks were trained by a statistical model produced using that results.Finally in order to optimize the objective function whichin this study is maximum achievable protrusion height, Genetic Algorithm was employed and optimal internal pressure and axial feedingsacquired to reach the goal.Byutilizing achieved loading paths and repeating the simulation one more time, maximum protrusion height attained without any deficiency.
\end{abstract}

\section{KEYWORDS}

Hydroforming,Y-shape,AxialFeeding, Counterpunch, NeuralNetwork, Genetic Algorithm

\section{INTRODUCTION}

In the early 1990's, hydroforming was introduced as an influential forming process for car industry because hydroformed parts were more qualitative, more robust and also demandedlower production costs [1]. However, there are some drawbacks such as lower production speed, high sensitivity of produced parts to load paths and expensive production equipment which are negligible compared with advantages. Tube hydroforming process is a well-developed technique in whichthe tube to be formed is placed inside a die and internal pressure is applied using a fluid which is usually water free from corrosive additives [2]. In order to prevent tube bursting from protrusion side through the process, both the ends of tube are moved by axial punches that this 
action is named axial feeding.An appropriate and flawless forming is guaranteed just when there is a correctrelationship between applied internal pressure and axial feeding relative to time.

Since when hydroforming technique was introduced, just a few analytical equations for anticipating formability of simple hydroformed parts like T-shapes and axisymmetric bulges have been derived and for more complex shapes accomplished analytical studies are not remarkable. Hence in the past, manufacturers tried to findthe best loading path by trialand error which demanded enormous time and cost and also obtained results were not necessarily the best ones.By considerable development in finite element method,they were dramatically used in hydroforming modeling.

Koc et.al [3], planned FEA simulations to develop the knowledge base about particular parts further using predetermined parameters varied over practical ranges.Asheesh Soniu [4],investigated the effect of internal pressure on stress distribution using LS-Dyna Explicit solver.G.T.Kirdli et.al [5], concluded that the thickness variation diminishes if die corner radius is increased and tube wall thickness is affecting internal pressure, while sustaining the same thinning pattern. Bathina Sreenivasulu, et.al [6], proved that the strain hardening coefficient has higher influence over formability of the tubes so that for forming of materials with higher value of " $n$ ", lower internal pressure needed.Jirathearanat et.al [7], demonstrated shorter the tube length before forming, achieved protrusion height is larger.Sung-Jong kang et.al [8], studied the effect of altering tube diameter by using FEA simulation LS-DYNA as a FE code by taking vehicle bumper rail section as product after hydroforming. They concluded that by increasing tube diameter slightly by $10 \%$, considerable reduction to about one-third in thinning rate and more uniform thickness distribution were predicted, whichever loading path was applied to the process.B.Sreenivasulu, et.al [9], modelled freebulge shaped tube die using Auto CAD, simulated THF using DEFORM-3D and found that wall thickness and thebranch height are most sensitive to friction, axial load, and internal pressure.

By combining optimization methods with FEA simulations, efficient ways of manufacturing perfect products with special properties will be obtained. Amongst all these properties, thickness uniformity and maximum achieved protrusion in parts with branches are the most important ones. In recent years a lot of researches have been done for finding optimal loading paths in various hydroforming processes.

For example, Yang et.al [10], combined optimization methods with FEA codes and determined loading path for tube hydroforming in closed dies. In terms of optimizing a T-shape, Fann et.al [11], found an optimum relationship between internal pressure and axial feeding applied in a hydroforming process. To do this, they utilized FEA method and conjugate gradient optimization algorithm simultaneously by setting a computer software to attain an optimized geometry and thickness distribution.Aydemir et.al [12], developed an adaptive design method for T-shape tube parts based on FEM to avoid wrinkling and necking. According to their method, internal pressure and axial feeding were applied with a constant slope. If applied values caused wrinkling, internal pressure would increase and axial feeding would diminish and in the case of bursting,previous change would apply in reverse.

Imaninejad et.al [13], acquired optimized loading path for an aluminium T-shape hydroforming using both optimization and FE methods. In their study, internal pressure was linear and constant through the process and optimization was just applied on axial feeding.KashaniZadeh et.al [14, 15], simulated the effect of friction coefficient, strain hardening exponent and fillet radius on 
protrusion height, thickness distribution and clamping and axial forces for an unequal $\mathrm{T}$ joint. They utilized numerical methods of optimization such as neural network to optimize the results. Objective function in their work was clamping force and constraint functions were wrinkling and minimum tube wall thickness.Koc et.al [3], used a special method named Low Cost Response surface Method to optimize geometrical parameters comprising tube length and protrusion diameter. Kadkhodayan et.al [16], firstly found a mathematical relationship between force variables and formability indicators using statistical analysis based on simulation results; then by importing resulted mathematical models into an evolutionary algorithm, yielded the best optimized loading path for a T-shape part.

Alaswad et.al [17], surveyed the effect of geometrical parameters upon wall thickness and protrusion height in a bi-layered T-shape component usingfinite element modelling (FEM) and then optimized the process by response surface methodology (RSM) for design of experiments(DOE).Ingarao et.al [18], optimized Y-shape hydroforming by combining numerical simulation, response surface method (RSM) and Pareto optimum solution finding method. They also utilized cascade optimization method to optimize applied pressure in another study. [19] Their method was a combination of Steepest Descent Method and Response Surface Method based on linear least squares.

Our objective in this study has firstly been surveying effects of various parameters including friction, fillet radius, mesh size, axial feeding and internal pressure on formability of Y-shape part using finite element simulation and then verifyingaccuracy and precision of simulation by comparing the attained results with experimental results [20] whereby it was finally confirmed that simulation results are highly close to the experimental results.

Then by repeating simulation in a certain number based upon various pressure and axial feeding values (as fundamental design variables) and by ignoring counter punch effect (as an independent variable), numerous protrusion height values as main output (goal variable) achieved. Also three indicators comprising calibration indicator (effective protrusion height), wrinkling indicator and bursting indicator were assumed as process constraints.

In this study, governing functions of hydroforming process were derived using both finite element simulation and neural network.Attained results of repeated simulations were utilized to train neural networks related to objective and constraints functions. Eventually by using genetic algorithm, loading path was optimized to achieve optimum goal variable which is maximum accessible protrusion height.

\section{Finite Element Simulation}

In order to simulate hydroforming, one of the best nonlinear finite element software has been used. Also since hydroforming of a y-shape part is a severely nonlinear process, explicit finite element method has been employed rather than implicit one. Explicit method formerly just used to analyse fast dynamic problems on which inertia had a determining effect. However, after a while it was shown that this method is even more appropriate than implicit method in solving some semi-static problems.Utilizing explicit method in semi-static problems needs specific attention. For instance, semi-static processes are done slowly and also time intervals in explicit method are infinitesimal, so if they are modelled by their actual time scale, they will demand an extra time cost. 
To resolve this problem, simulation should be done faster but it can in turn cause some inertial drawbacks. So declining simulation time, while inertial effects do not become problematic, is quite an art.In reality, process's time usually lasts between 0.5 to 10 seconds and simulation's time often lasts between 10 milliseconds to 300 milliseconds.

In explicit method if any time interval becomes bigger than a specific value, solution will become unstable. This value is named stability limit and is defined as below:

$$
\Delta \mathrm{t}_{\text {stable }}=\mathrm{L}^{\mathrm{e}} / \mathrm{C}_{\mathrm{d}}
$$

$\mathrm{L}^{\mathrm{e}}$ and $\mathrm{C}_{\mathrm{d}}$ are respectively element length and wave velocity in that specific material.

$$
C_{d}=\sqrt{ }(E / \rho)
$$

$\mathrm{E}$ is Young modulus and $\rho$ is material density. Obviously any rise in density certainly increases stability limit.In some cases such as a model with tiny elements which usually decreases stability, increasing density can cause problem to become more stable.

By allocating higher density which is named mass scaling just to this part of model, answers are usually achieved easier. Of course at the end of simulation, internal and kinetic energy diagrams should be checked not to cause dynamic instabilities.After allocating mass scaling to the model, maximum kinetic energy should not often be higher than 10 per cent of internal energy.

Initial dimensions and properties of tube utilized in this study have been demonstrated in table 1.

Table 1. Initial Dimensions and Properties of Tube

\begin{tabular}{|l|l|l|l|l|l|l|l|l|}
\hline $\mathbf{E}(\mathbf{G P a})$ & $\mathbf{K}(\mathbf{M P a})$ & $\mathbf{v}$ & $\mathbf{n}$ & $\mathbf{t o}(\mathbf{m m})$ & $\boldsymbol{\mu}$ & $\mathbf{L}(\mathbf{m m})$ & $\mathbf{D i}(\mathbf{m m})$ & $\mathbf{D o}(\mathbf{m m})$ \\
\hline 198 & 1.471 & 0.35 & 0.584 & 1.5 & 0.05 & 320 & 47 & 50 \\
\hline
\end{tabular}

Also initial and final geometry of initial tube and final part, position of punches and geometry of die have been represented in figure 1 . 


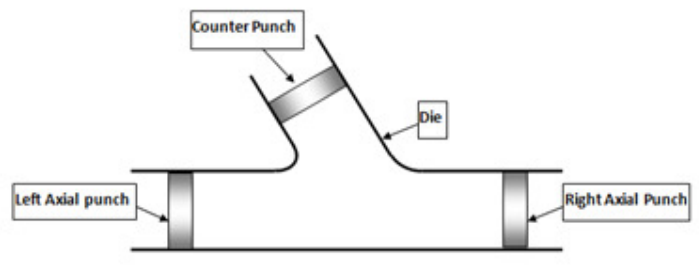

(a)

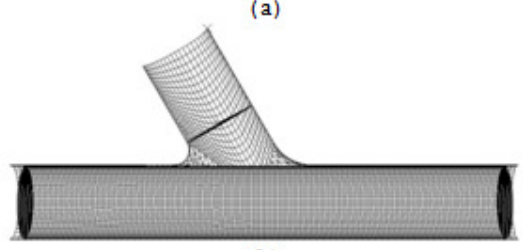

(b)

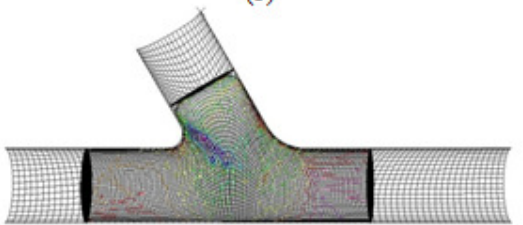

(c)

Figure 1. (a) Schematic of Punches and Die (b) Initial Geometry of Tube and (c) Final Geometry of YShape Part

In reality and in finite element simulation of a hydroforming process in order to produce or model a part with protrusion, the way and amount of applying axial feeding, internal pressure and counter punch displacement are extremely influential in achieving a perfect part.

In figure 2 the curves of these three important factors which are applied to modela desirable part in current study, have been depicted. The curve of applied internal pressure has been obtained by connecting values resulted from definitions of yield, bursting and calibration pressures as given in Eqs. (1) to (3), respectively [14]:

$$
\begin{gathered}
(P i)_{y}=\sigma_{y} \frac{2 t_{0}}{D_{0}-t_{0}} \\
(P i)_{b}=\sigma_{u} \frac{4 t_{0}}{D_{p}-t_{0}} \\
(P i)_{\max }=\frac{2}{\sqrt{3}} \sigma_{f}\left[\ln \frac{r_{b}}{r_{b}-t_{0}}\right]
\end{gathered}
$$

Where, $t_{0}$ is the initial wall thickness, $D_{0}$ the tube diameter, $D_{p}$ the protrusion diameter, $r_{b}$ the smallest die cornerradius, $\sigma_{\mathrm{f}}$ the flow stress of the material, $\sigma_{\mathrm{y}}$ the yield strength of the material and $\sigma_{\mathrm{u}}$ the ultimate tensile strength ofmaterial.

Left and right axial feedings have respectivelybeen applied by ratio of 2:1. These values have been derived from a study [3] that its experimental results have been used to verify obtained results of current article.Some analytical equations have been employed to determine these primary values as initial assumptions and then they are altered during simulation to achieve the 
International Journal of Recent Advances in Mechanical Engineering (IJMECH) Vol.5, No.4, November 2016 best input values. Any of these values can even be applied as a primary guess for more complex parts.

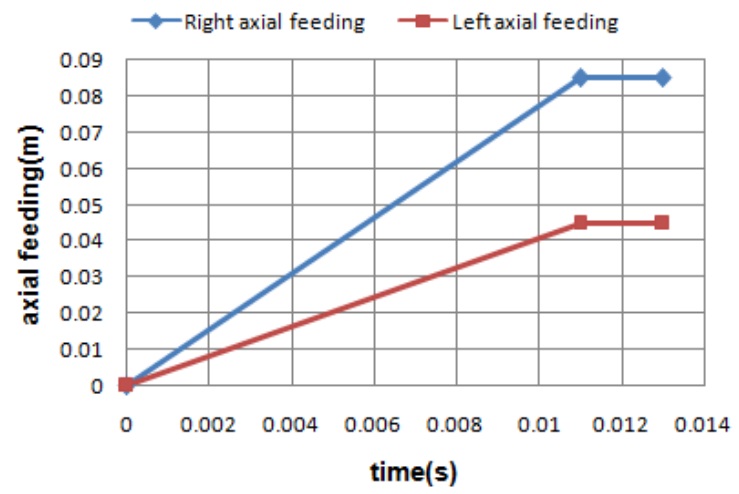

(a)

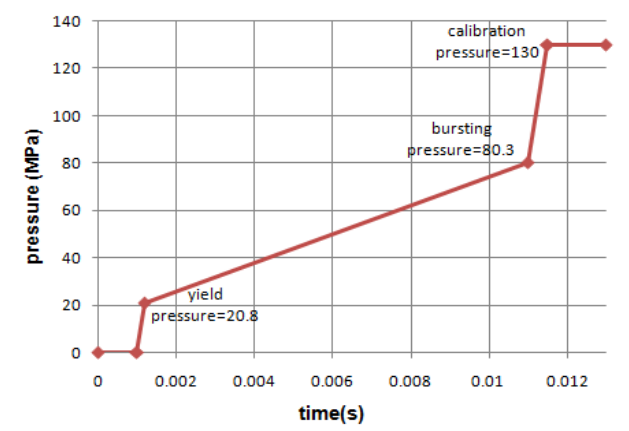

(b)

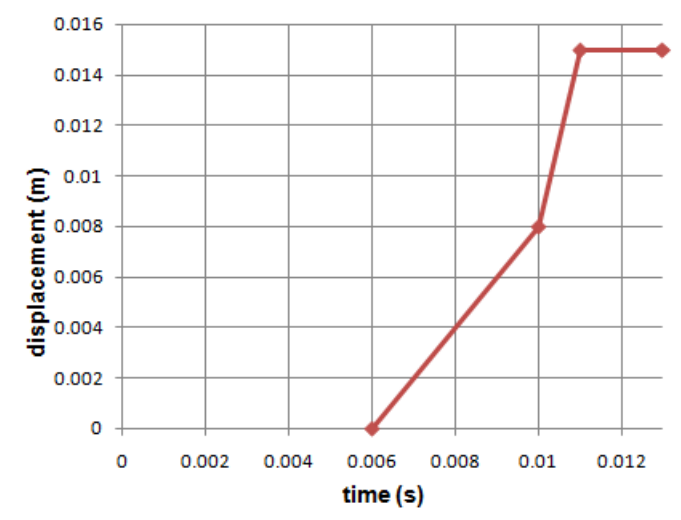

(c)

Figure 2. Applied (a) Axial Feeding (b) Internal Pressure (c) Counterpunch Displacement Curves

Since current model is symmetric relative to plane YZ, it hashalfbeensimulated. To define the contact between tube and die, penalty contact algorithm has been employed. As a general rule of thumb if the ratio of tube radius to tube thickness is bigger than 10 , shell elements can be used to model tube instead of brick elements. 
As mentioned earlier a way to increase simulation speed is mass scaling. There is another way to do so and that is increasing hydroforming time artificially during simulation. In forming process simulations usually a time scale as much as 1000 times is used. In this study, the whole time of forming is 13 seconds, so total simulation time is deemed 13 milliseconds. Also material of the tube in this article is SS304 which its Flow Stress is defined as $\sigma=1.471(0.06+\bar{\varepsilon})^{0.584}$.

\section{Simulation Results}

\subsection{Thickness Change Curve}

A comparison between upper edge tube thickness obtained from experimental results and FEM has been demonstrated in figure 3. Based on these results it is apparent that both the curves are considerably similar which can be deemed as a sign of simulation precision.

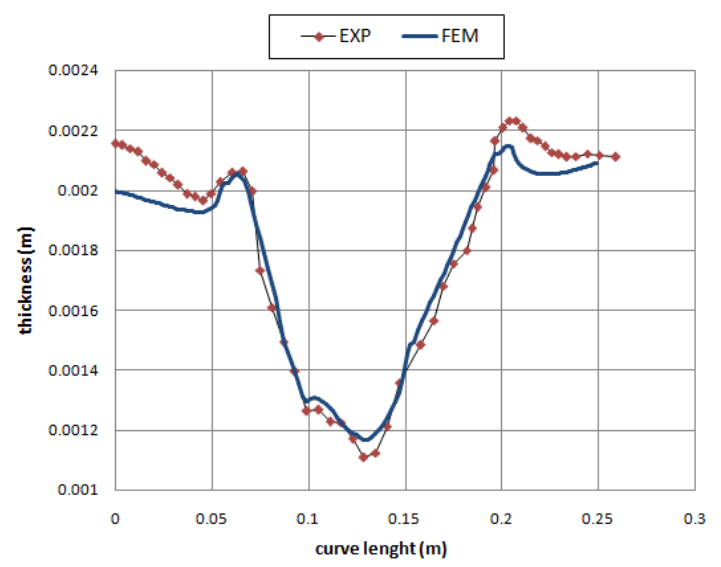

Figure 3. thickness distribution comparison between FEM and experimental results

\subsection{INTERNAL ENERGY AND TOTAL KINETIC ENERGY}

Internal energy and total kinetic energy curves have been demonstrated in figure 4. According to the first figure, internal energy rate is ascending. It is true because during the process internal pressure, friction force and resistant force of counter punch are rising. But in the second figure total kinetic energy fluctuates during process.

From the beginning of simulation until time 2.5 milliseconds, as a result of axial punches' movement and declination of tube-die contact surface and friction force, kinetic energy goes up dramatically and reaches to its maximum value. By entering tube elements into the vacant part of die and an increase in tube-die contact in corners and also a rise in internal energy and consequently friction force, kinetic energy declines up to time 5.5 milliseconds. By starting counter punch's movement, it increases again till time 7.6 millisecond and then by increasing counter punch's resistant force against elements' movement until time 9.5 milliseconds, it goes down. Between times 10 to 11 milliseconds by a remarkable increase in counter punch velocity, kinetic energy rises again and by stopping the counter punch at the end of process it diminishes rapidly and reaches 0 . 
International Journal of Recent Advances in Mechanical Engineering (IJMECH) Vol.5, No.4, November 2016

According to the graphs, the proportion of maximum kinetic energy to maximum internal energy is about 0.015 (up to 0.1 is acceptable) which demonstrates that allocating mass scale as much as 50 times does not cause any problem for simulation.

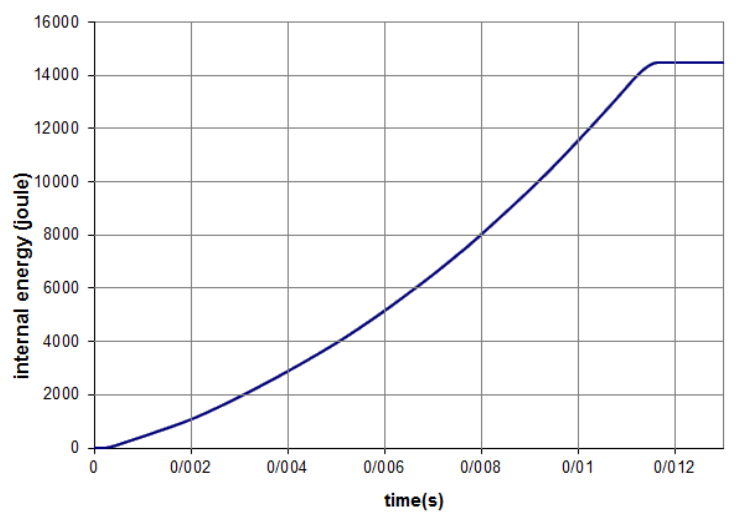

(a)

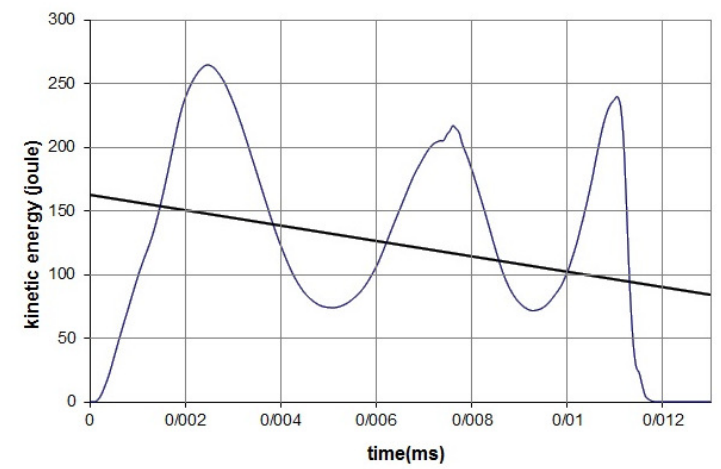

(b)

Figure 4.(a) Internal energy and (b) total kinetic energy

\subsection{COUnTERPunCH ForCE}

Figure5(a) represents a comparison between counterpunch force curves obtained from experimental results and FEM results which shows a remarkable analogous between them. Also figure 5(b) yields axial punches' force results. Knowing counter punch force and axial punches' forces is mandatory because without having enough information about them, selecting an appropriate equipment to manufacture Y-shape part is probably uneconomical. 
International Journal of Recent Advances in Mechanical Engineering (IJMECH) Vol.5, No.4, November 2016

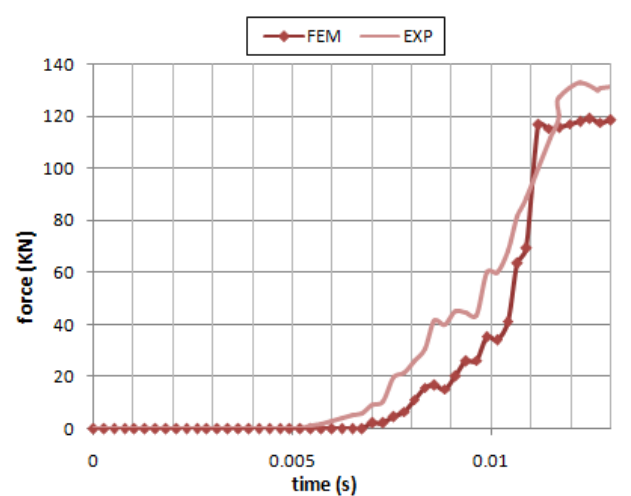

(a)

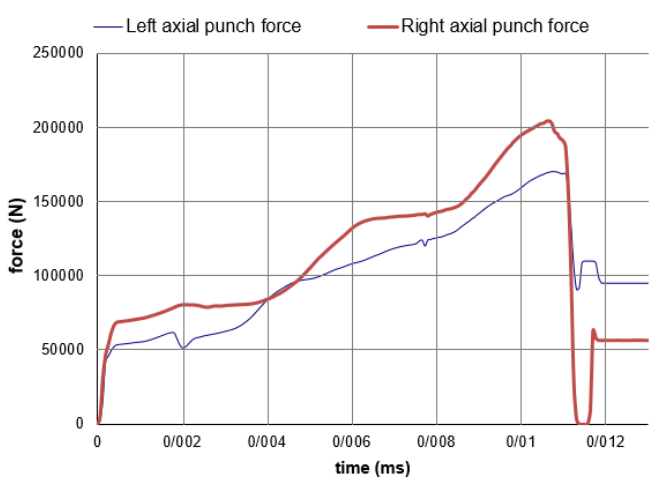

(b)

Figure 5: (a) counterpunch force comparison between FEM and experimental results and (b) axial punch forces

\subsection{EFFEct Of COUnTERPunCh ON THICKNESS Distribution}

Utilizing counterpunch decreases probability of thinning remarkably thereby lowering likelihood of bursting. To prove thisnotion, tube thickness through path 2 (figure 8) has been considered and resulting data have been shown in figure 6.Based on the results evidently using counter punch helps tube to be modelled more uniform. In both simulations, internal pressure and axial feedings have been considered identical.

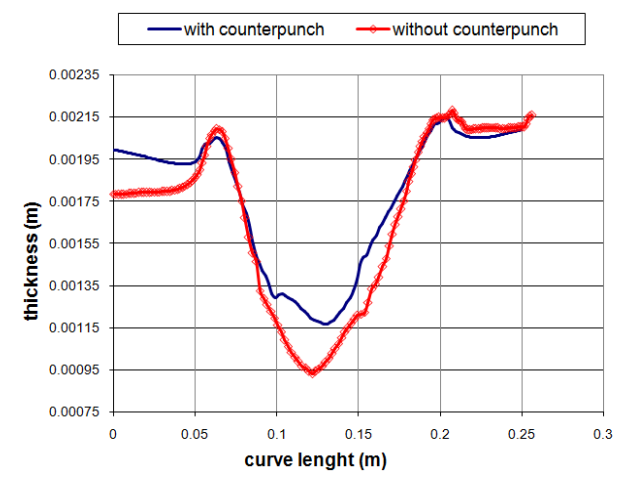

Figure 6.Effect of counterpunch on thickness distribution 


\subsection{EFFECT Of Friction COEFFICIENT}

Importance of friction is due to direct relationship between friction coefficient and resistant contact force. High amounts of friction prevents an easy material movement in the die through the process.Consequently to reach an appropriate amount of protrusion height, higher amounts of force should be applied at two ends of tube which in turn needs to a more powerful press and higher production costs.In figure 7, three different friction coefficients have been employed to demonstrate their effects on thickness distribution through tube upper edge at the end of process and left applied axial force.

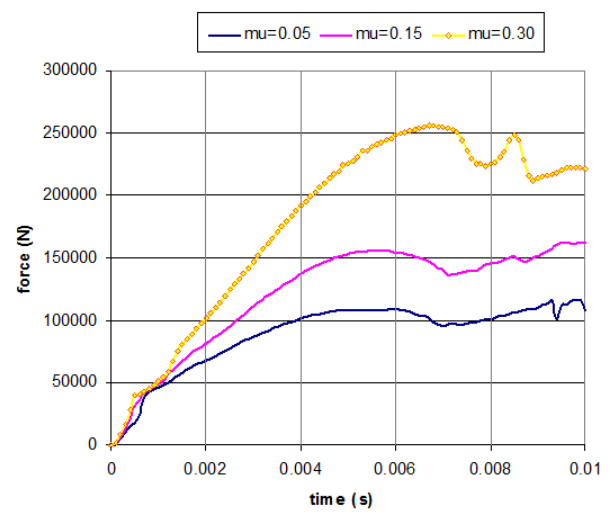

(a)

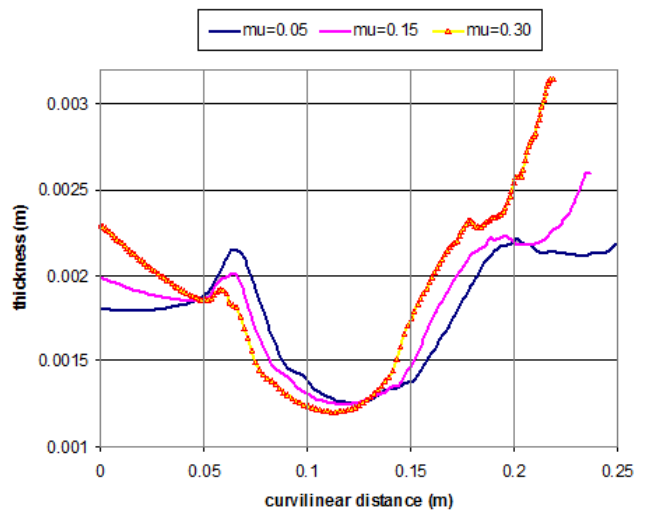

(b)

Figure 7. effects of applying different friction coefficients on (a) Left axial punch force and (b) thickness distribution

\subsection{Effect Of Fillet Radius (Corner Radius Of Protrusion) On Formability}

Two upper and lower tube edges have been respectively investigated through hypothetical paths at the end of process to represent the influence of fillet radius on thinning and wrinkling. These two paths have been shown in figure 8 . 


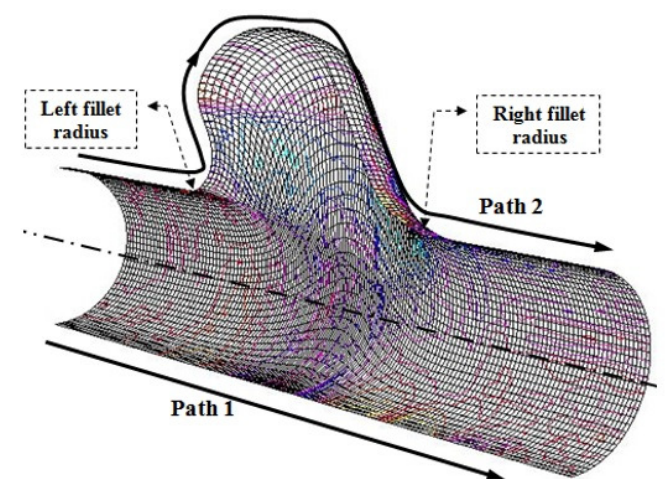

Figure 8: Hypothetical paths to verify effects of fillet radius on formability

In figure 9 resulting curves of thickness and tube-die distance are shown.As in figure 9(a) is evident, any change in fillet radius on both left and right side can remarkably cause wrinkling through path1 so that by decreasing fillet radius on both corners of protrusion, probability of forming wrinkles increases considerably. The reason is by decreasing fillet radius, composing material of tube cannot flow gradually with a gentle slope and material veers severely while entering to the vacant part of die whereby protrusion height decreases dramatically. Also by considering figure 9(b) it appears that by increasing fillet radius, tube thickness remains moreunchangeable and thinning in minimum point is lower than two other curves.

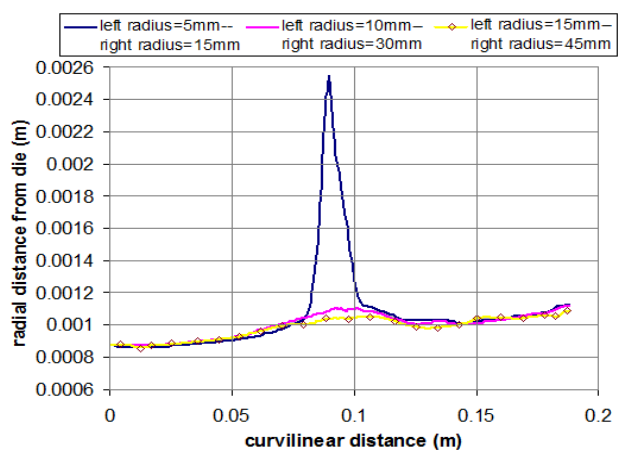

(a)

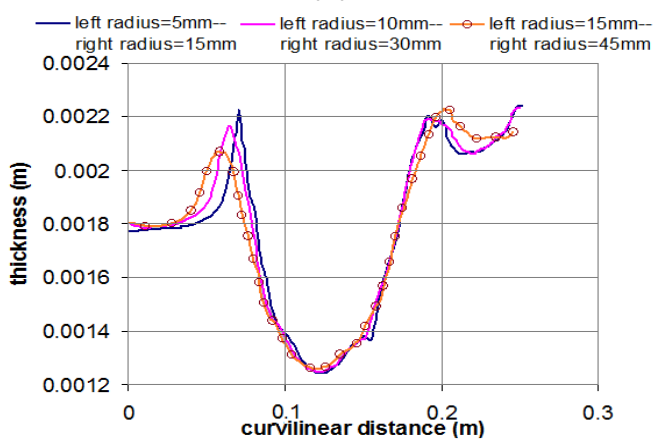

(b)

Figure 9. effect of fillet radius on (a)wrinkling through path 1 and (b) thickness distribution through path 2 


\subsection{EfFect Of Element Size ON Simulation Results}

Size of elements is quite important to predict wrinkling so that as infinitesimal elements are employed,predictability of wrinkles increases but simultaneously calculation time rises remarkably.On the contrary if big elements are used,calculation time will decrease, however, most likely wrinkles won't be recognized evidently. In order to survey above mentioned effect, lower edge of Y-shape part is considered at final step. Figure 10 clearly shows effect of element size onanticipating wrinkles.

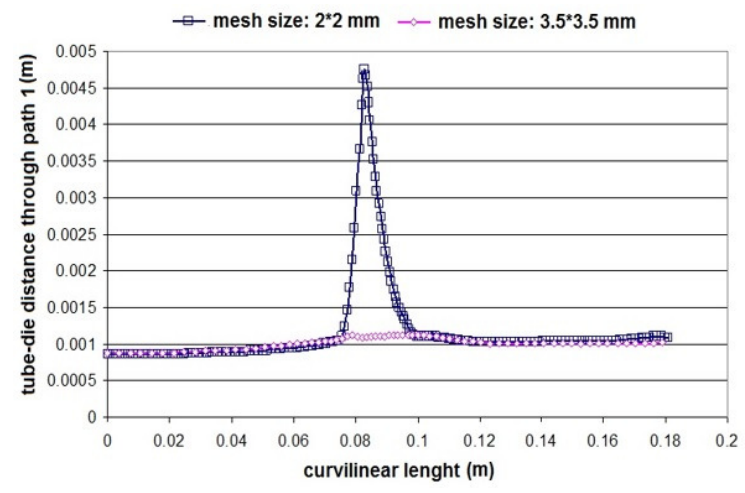

Figure 10.Effect of element size on wrinkling prediction

\section{Optimization Problem}

Y-shape hydroforming comprises three parameters: a) left and right axial feeding, b) applied internal pressure and c) counterpunch force. Since the most important goal in current simulation is to reach maximum protrusion height and by considering the fact that importingcounterpuncheffectinto optimization problem not only doesn't really help but also makes it more complicated, onlyaxial feedings and internal pressure effectsas optimization problem variables have been taken into account.

\subsection{OBJECTIVE FUNCTION}

The final goal in this optimization problem is finding the best combination of axial feedings and applied pressure related to time so that protrusion height reaches to its maximum accessible amount which is recognized as adesirable parameter for such parts.

$$
f(x)=\operatorname{Max}\left(H p_{\text {tube }}\right)
$$




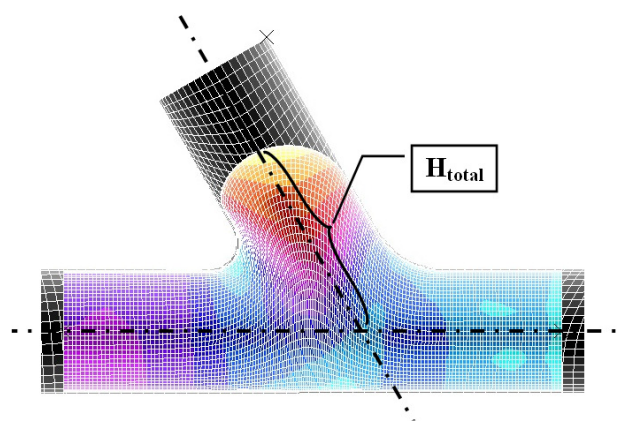

Figure 11. total protrusion height definition

\subsection{Constraint Functions}

Three different constraints are needed in this optimization problem.

\subsubsection{MAXIMUM THINNING CONSTRAINT (BURSTING INDICATOR):}

While protrusion is reaching to its highest amount, an excessive thinning may be generated at top right side of it. So to limit and constraint maximum allowable thinning for the part seems mandatory.[4]figure 12 demonstrates surveyed path to measure thickness distribution for thinning investigation.

$$
g_{1}(x)=\operatorname{Max}\left|\left[\frac{h_{i}-h_{o}}{h_{o}}\right]\right|<\varepsilon_{1}
$$

Which $h_{i}$ is element thickness at final step of simulation and $h_{o}$ is initial tube thickness. In this problem based on existing criteria[3] $\varepsilon_{1}=25 \%$.

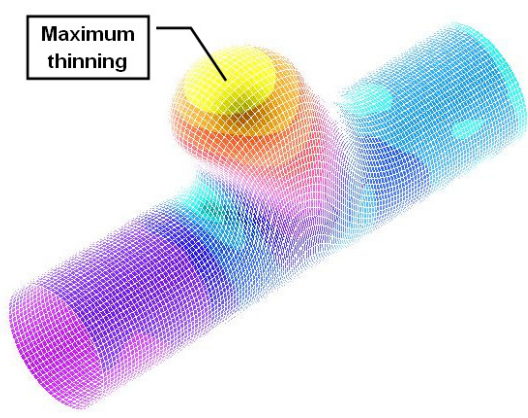

Figure 12. maximum thinning criterion

\subsubsection{PROTRUSION CONSTRAINT (CALIBRATION INDICATOR)}

Based on this constraint useful height of protrusion shown in figure 13 should not be less than certain value which in this study is $60 \mathrm{~mm}$.

$$
g_{2}(x)=H_{\text {useful }}>\varepsilon_{2}=60 \mathrm{~mm}
$$




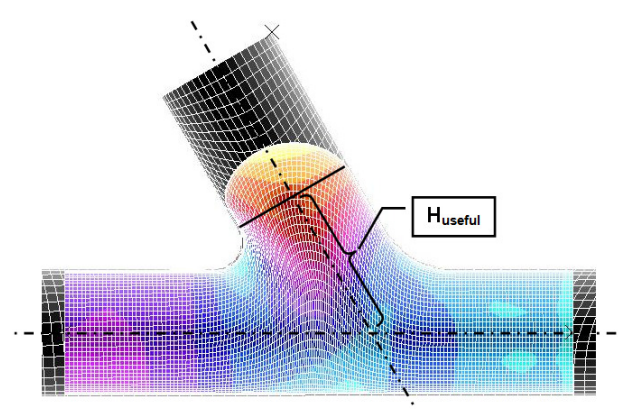

Figure 13. useful protrusion height definition

\subsubsection{Tube To Die Distance CONSTRAint (WrinkLing INDICATOR)}

In order to preventwrinkling in final simulated part, this constraint has been defined which is perpendicular distance between tube-die surfaces through twospecified path at final step of simulation. If this distance exceeds a certain value it means hydroforming has not been successfully done and the part has not been completely formed or has wrinkled. In order to investigatespots with the most probability of wrinkling, two above mentioned profiles have been considered and demonstrated in figure 14 in final step of simulation at which tube-die distance is recorded and compared with indicator.

$$
g_{3}(x)=\operatorname{Max}\left(d_{i}^{1}, d_{i}^{2}\right) \leq \varepsilon_{3}
$$

$d_{i}^{1}$ and $d_{i}^{2}$ are respectively tube to die distance through profile 1 and profile 2 . The upper limit of this constraint is usually determined between $0.5 \mathrm{~h}_{\mathrm{o}}$ and $\mathrm{h}_{\mathrm{o}}$ which $\mathrm{h}_{\mathrm{o}}$ is initial thickness of tube. In this study $\varepsilon_{3}=1.5 \mathrm{~mm}$.

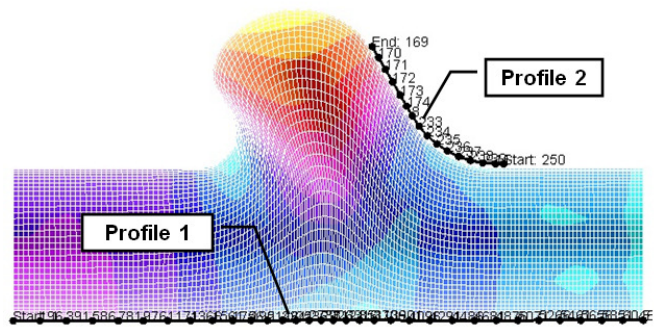

Figure 14. profiles utilized to investigate wrinkling

\subsection{NeURAL NetWORK}

Thus far objective function, constraint functions and design variables have been introduced and we understood all of them should be available for optimizing the Y-shape part simulation; but the biggest obstacle in the way of THF optimizing process especially to optimize those parts with enormous complexity is that there is no precise analytical relationship among various parameters 
of process. So by considering neural networks' remarkable privilege in learning and then finding a good relationship between numerical data which are usually in form of input and output couples and also their capability in facing an untrained input and yielding an appropriate output, they have necessarily been used in this study.

\subsubsection{EXTRACTING NUMERICAL DATA}

In order to trainappropriate required neural networks, table 2 comprising various combinations of internal pressure and axial feeding and also resulting values of constraint functions attained after frequently running finite element software, was established.Altogether simulation was run56 times.49 resultant data were used to train neural network and the rest were used as test data.

Table 2. used values of internal pressure and axial feeding in order to repeat

\begin{tabular}{|l|l|}
\hline Applied internal pressure (Mpa) & Left axial feeding/ Right axial feeding (mm) \\
\hline 40 & $35.0 / 70.0$ \\
\hline 50 & $38.0 / 76.0$ \\
\hline 55 & $39.5 / 79.0$ \\
\hline 60 & $41.0 / 82.0$ \\
\hline 70 & $42.5 / 85.0$ \\
\hline 75 & $44.0 / 88.0$ \\
\hline 80 & $47.0 / 94.0$ \\
\hline 90 & - \\
\hline
\end{tabular}

\subsubsection{USING NNTOOL OF MATLAB SOFTWARE}

In order to access to an influential relationship between every indicator and problem inputs, 4 neural networks were defined separately each of which can be deemed as a function.

Table 3 demonstrates the number of layers, neurons and type of motivating functions used in each layer of 4 designed functions. In figure 15 the schematic network diagram related to objective function (protrusion height) has been shown. After defining input/output data and the network in MATLAB, program ran frequently till the most appropriate network was trained.

Table 3. required neural networks

\begin{tabular}{|l|l|l|l|l|l|}
\hline Neural network & Input layer & First layer & Second layer & Output layer \\
\hline \multirow{2}{*}{$\begin{array}{l}\text { Objective function } \\
\text { (Protrusion height) }\end{array}$} & Number of neurons & 2 & 8 & & 1 \\
\hline & Transfer function & & tansig & & purelin \\
\hline $\begin{array}{l}\text { Wrinkling function } \\
\text { (tube to die distance) }\end{array}$ & Number of neurons & 2 & 7 & 5 & 2 \\
\cline { 2 - 7 } & Transfer function & & tansig & tansig & purelin \\
\hline $\begin{array}{l}\text { Bursting function } \\
\text { (minimum thickness) }\end{array}$ & Number of neurons & 2 & 10 & & 1 \\
\cline { 2 - 6 } & Transfer function & & tansig & & purelin \\
\hline $\begin{array}{l}\text { Calibration function } \\
\text { (Useful protrusion } \\
\text { height) }\end{array}$ & Number of neurons & 2 & 7 & & 1 \\
\cline { 2 - 6 } & Transfer function & & tansig & & purelin \\
\hline
\end{tabular}

It is necessary to be said that determining appropriate structure of every network should be done by trial and error and there is no explicit method to do that. [21] 


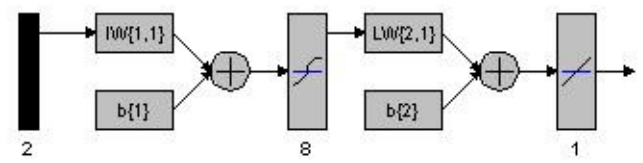

Figure 15: schematic network diagram for objective function

Network training and test data curves and their convergenceinto each other have been shown in figure 16. Evidently test data satisfactorily conformto the training data.

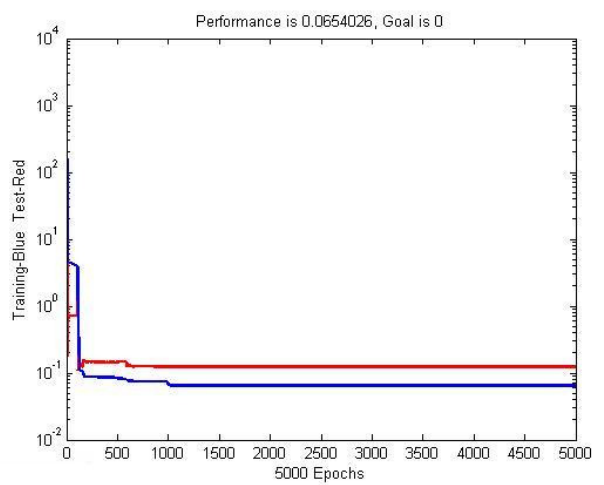

Figure 16. neural network training data for objective function(blue) and test data(red)

Figure 17 demonstrates a comparison between the attained databyobjective functionneural network andsimulation values from test data which are acceptably analogous and proves that neural network has been trained efficiently and can be trusted to be used in next stage which is simulation optimizing.

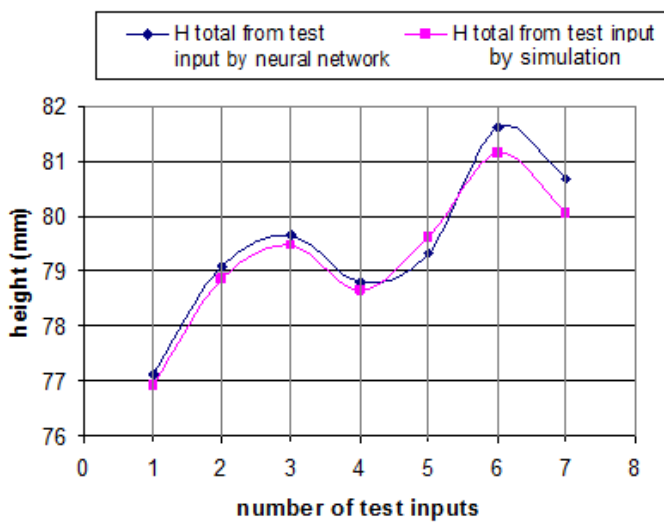

Figure 17: values attained byobjective functionneural network and simulationrelated to test data 


\subsubsection{GENETIC AlgORITHM}

After defining objective and constraints functions using neural network, an optimization algorithm should be applied to achieve optimum value for objective indicator.There are various algorithms to optimize problems but one of the best ones is genetic algorithm. Some advantages of genetic algorithm are as follows:ability to do optimization with both continuous and discontinuous variables, no need of gradient-based data, ability to work with numerous variables, appropriate for running on parallel computers and ability to work with numerical data, experimental data and analytical functions. In this study, genetic algorithm just uses objective function and fitness function for determining searching path. Furthermore possibility of reaching general optimum point is considerably high and probability of being trappedin local optimum points is remarkably low.

Figure 18 represents fitness value diagram after several repetitions.

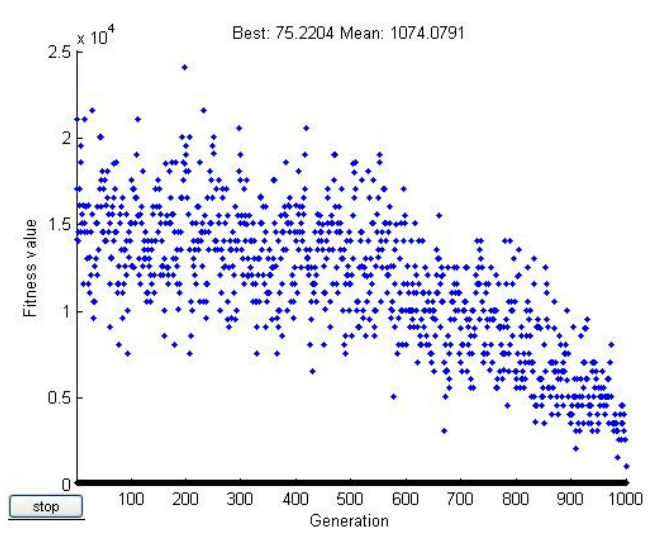

Figure 18: fitness value of each generation

Relying on this optimization, input values in proportion to optimized output are as follows:

Table 4: optimized input data

\begin{tabular}{|l|l|}
\hline internal pressure $(\mathrm{Mpa})$ & 83.87 \\
\hline right axial feeding $(\mathrm{mm})$ & 89.95 \\
\hline Left axial feeding $(\mathrm{mm})$ & 44.975 \\
\hline
\end{tabular}

Using values from table 4 and by inserting them in each neural network, related output shown in table 5 is obtained.

Table 5: resulting output from neural networks using optimized data

\begin{tabular}{|l|l|}
\hline Neural network & Estimated value (mm) \\
\hline Objective function (protrusion height) & 87.1049 \\
\hline Tube to die distance (profile 1) & 1.14 \\
\hline Tube to die distance (profile 2) & 1.023 \\
\hline Minimum thickness & 1.1251 \\
\hline
\end{tabular}


By importing above values as input data in finite element software, results demonstrated in table 6 are obtained.

Table 6: resulting output from finite element software using optimized data

\begin{tabular}{|l|l|}
\hline Finite element analysis & Value (mm) \\
\hline Objective function (protrusion height) & 86.89 \\
\hline Tube to die distance (profile 1) & 1.08 \\
\hline Tube to die distance (profile 2) & 1.09 \\
\hline Minimum thickness & 1.173 \\
\hline
\end{tabular}

By comparing tables 5 and 6 results, it is completely clear that both the results are dramatically similar.

\section{Conclusions}

Y-shape parts hydroforming needs appropriate selection of numerous parameters, i.e. the internal pressure, the axial feedings at both left and right side and the counter punch displacement. In order to reduce the cost and time of choosing the values of these parameters, utilizing finite element method can be extremely helpful since according to the recent studies, FEM results are highly reliable. However, FEM can just be helpful in a case that a manufacturer wants to verify efficiency of loading path before production process and choosing the best parameters are not necessarily guaranteed. So employing optimization methods like Neural Network and Genetic Algorithm and combining them with FEA yields the best results in production process.

\section{REFERENCES}

[1] M. Ahmetoglu and T. Altan, "Tube hydroforming, state-of-the-art and future trends," Journal of Materials Processing Technology, vol. 98, pp. 25-33, 2000.

[2] M. Shabbir, O. Ahmad and k. Narasimhan, "Finite element analysis for Optimizing process parameters in tube hydroforming," in IDDRG, Switzerland, 2013.

[3] M. Koc, T. Allen, S. Jiratheranat and T. Altan, "The use of FEA and design of experiments to establish design guidelines for simple hydroformed parts," International Journal of Machine Tools \& Manufacture, vol. 40, pp. 2249-2266, 2000.

[4] S. Asheesh, V. Jyoti and A. .. Sharma, "Finite element analysis of component developed by tube hydroforming," International Research Journal of Mathmatics, Engineeing and IT, 2014.

[5] G. Kirdli, L. Bao, P. Mallick and Y. Tian, "Investigation of thickness variation and corner filling in tube hydroforming," Journal of Material Processing Technology, vol. 133, pp. 287-296, 2003.

[6] S. Bathina and B. Reddy, "Experimental analysis of tube hydroforming," Int. J. Mech. Eng. \& Rob. Res., 2014.

[7] S. Jirathearanat, C. Hartl and T. Altan, "Hydroforming of Y-shapes-product and process design using FEA simulation and experiments," Journal of Materials Processing Technology, vol. 146, pp. 124-129, 2004.

[8] K. Sung-Jong, K. Hyoung-Kwang and K. Beom-Soo, "Tube size effect on hydroforming formability," Journal of Materials Processing Technology, vol. 160, pp. 24-33, 2005.

[9] B. Sreenivasulu, G. Prasanthi and T. Naresh Kumar, "Simulative analysis of Tube Hydroforming process," International Journal of, 2013.

[10] J. Yang, B. Joen and S. Oh, "Design Sensitivity Analysis and Optimization of the Hydroforming Process," J. Mater. Proc.Technol., vol. 113, pp. 666-672, 2001.

[11] J. Fann and P. Hsiao, "Optimization of loading conditions for tube hydroforming," Journal of Materials Processing Technology, vol. 140, pp. 520-524, 2003. 
[12] A. Aydemir, J. de Vree, W. Brekelmans, M. Geers, W. Sillekens and R. Werkhoven, "An adaptive simulation approach designed for tube hydroforming processes," Journal of Materials Processing Technology, vol. 159, pp. 303-310, 2005.

[13] M. Imaninejad, G. Subhash and A. Loukus, "Loading path optimization of tube hydroforming process," International Journal of Machine Tools \& Manufacture, vol. 45, pp. 1504-1514, 2005.

[14] H. Kashani Zadeh and M. Mosavi Mashhadi, "Finite element simulation and experiment in tube hydroforming of unequal T shapes," Journal of Materials Processing Technology, vol. 177, pp. 684$687,2006$.

[15] F. Mohammadi, H. Kashani Zadeh and M. Mosavi Mashhadi, "optimization using finite element analysis,neural network and experiment in tube hydroforming of aluminum T joints," vol. 221, pp. 1299-1305, 2007.

[16] M. Kadkhodayan and A. Erfani-Moghadam, "An investigation of the optimal load paths for the hydroforming of T-shaped tubes," Int J Adv Manuf Technol, vol. 61, pp. 73-85, 2012.

[17] A. Alaswad, K. Benyounis and A. Olabi, "Employment of finite element analysis and Response Surface Methodology to investigate the geometrical factors in T-type bi-layered tube hydroforming," Advances in Engineering Software, vol. 42, pp. 917-926, 2011.

[18] G. Ingarao, R. Di Lorenzo and M. F., "Internal pressure and counterpunch action design in Y-shaped tube hydroforming processes: A multiobjective optimisation approach," Computers \& Structures, vol. 87, pp. 591-602, 2009.

[19] R. Di Lorenzo, G. Ingarao and F. Chinesta, "Integration of gradient based and response surface methods to develop a cascade optimisation strategy for Y-shaped tube hydroforming process design," Advances in Engineering Software, vol. 41 No. 2, pp. 336-348, 2010.

[20] S. Jirathearanat, advance method for finite element simulation for part and process design in tube hydroforming, Department of mechanical engineering- The Ohio State University, 2004, pp. 124-129.

[21] M. T. Hagan, H. B. Demuth and M. H. Beale, Neural Network Design, Boston: PWS Publishing, 1996.

\section{AMIR RAHIMI}

I was born in 1983. I have a master's degree in mechanical engineering from Isfahan university of technology, Iran. I have been working for National Iranian Oil Company since 7 years ago. Now I am a senior technical inspector. My interest areas are metal forming, MEMS, NEMS, computer simulation. And I am expert in CATIA, ABAQUS, COMSOL and MATLAB.

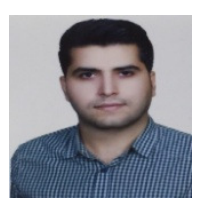

